\title{
Illicit tobacco trade in Georgia: prevalence and perceptions
}

\author{
Megan Little, ${ }^{1}$ Hana Ross, ${ }^{1}$ George Bakhturidze 다, ${ }^{2,3}$ lago Kachkachishvili ${ }^{4}$
}

- Additional material is published online only. To view please visit the journal online (http://dx.doi.org/10.1136/ tobaccocontrol-2018-054839)

${ }^{1}$ Economics, Southern Africa Labour and Development Research Unit, University of Cape Town, Cape Town, South Africa

${ }^{2}$ Tobacco Control Research, FCTC Implementation and Monitoring Center in Georgia, Tbilisi, Georgia

${ }^{3}$ Health Promotion Research, Georgian Health Promotion and Education Foundation, Tbilisi, Georgia

${ }^{4}$ Sociology and Social Work Department, Ivane Javakhishvili Tbilisi State University, Tbilisi, Georgia

\section{Correspondence to}

Megan Little, Economics, Southern Africa Labour and Development Research Unit, University of Cape Town, Cape Town, 7700, South Africa: firdaleconsulting@gmail.com

Received 12 November 2018 Revised 9 December 2018 Accepted 12 December 2018 Published Online First 18 January 2019

\section{ABSTRACT}

Background In lower-income and middle-income countries, limited research exists on illicit tobacco trade and its responsiveness to taxation. Tobacco taxes are critical in reducing tobacco consumption, thereby improving public health. However, the tobacco industry claims that tax increases will increase illicit tobacco trade. Therefore, research evidence on the size of the illicit cigarette market is needed in Georgia and other low-income and middle-income countries to inform tobacco tax policies.

Methods In 2017, a household survey using stratified multistage sampling was conducted in Georgia with 2997 smokers, to assess illicit tobacco consumption. Smokers were asked to show available cigarette packs to the surveyors. These were examined for tax stamps and health warnings which allowed for an assessment of illegal cigarette consumption in Georgia.

Findings The packs shown to surveyors suggest illicit cigarette trade is low (1.5\%), although with regional differences, as illicit cigarette packs were present in $6 \%$ of the households in Zugdidi. Most illicit cigarettes were purchased at kiosks or informal outlets. This estimate might be conservative, as $28 \%$ of respondents did not show any packs to the surveyors.

Conclusions Despite recent tobacco tax increases, illicit cigarette trade in Georgia seems to be negligible. The market is more vulnerable to illicit cigarette trade close to the border with Abkhazia (near Zugdidi). Tighter control or ban of tobacco sales at kiosks and informal outlets may reduce illicit cigarette trade. Further investigation is planned to better understand why a large proportion of survey participants said they had no pack available at home.

\section{INTRODUCTION}

Georgia has had a persistently high male smoking prevalence which even increased from $53.3 \%$ in 2001 to $57 \%$ in 2016. Women smoke less, but their smoking prevalence is also on the rise- $6.3 \%$ in 2001 and $12.2 \%$ in 2016. ${ }^{12}$

The Republic of Georgia used to be an important source of tobacco leaves and manufactured cigarettes for the whole the Soviet Union. ${ }^{3}$ However, the Soviet Union's fall in the early 1990s led to the collapse of the Georgian tobacco industry and soon the domestic market was flooded with international brands. ${ }^{4}$ Initially (1991-1997), no taxes were levied on cigarettes. When they were introduced in late 1997, the locally manufactured cigarettes enjoyed substantially lower tax rates. ${ }^{3}$ The specific excise rates remained constant until 2004 allowing their real value to erode by inflation. ${ }^{4}$
The new government coming to power in 2004 decided to double and triple taxes for imported filtered and domestic filtered cigarettes, respectively. In preparation for this increase, tobacco companies prepurchased tax stamps (introduced in 1999) with the lower 2004 value, to use in their 2005 sales. This resulted in an artificial tax revenue increase in 2004 followed by a sharp fall in early 2005, when the new tax came into effect. Tobacco companies then asserted that the tax revenue fall was driven by a sharp increase in illicit trade from $10 \%$ in 2003 to $65 \%$ in post- $2005 .^{3}$ This persuaded the government to lower taxes by $30 \%-40 \%$ in 2006, despite the fact that tobacco excise revenue was $47 \%$ higher in real terms in 2004/2005 compared with 2002/2003. ${ }^{3}$ The cigarette excise taxes began rising thereafter, but only reached their 2005 nominal values in $2010 .^{3}$ The industry's illicit trade argument, based on their own assessment of the illicit trade market, resulted in a real setback to tobacco tax policy in Georgia.

Until now, no nationally representative estimates of the size of the illicit cigarette market in Georgia have been published in peer-reviewed literature. Some surveys conducted in the early 2000s indicated a substantial penetration of illicit cigarettes in Georgia-between one-third and two-thirds of the market. ${ }^{356}$ Subsequent reports suggested that government reforms in 2004 substantially reduced the size of the illicit cigarette market $^{7}$ and in 2017, the Head of the Healthcare Committee of the Georgian Parliament reported that the illicit cigarette market share was less than $3 \%$ of total consumption. $^{8}$

This study seeks to understand the consumption of illicit tobacco products and general perceptions of illicit tobacco trade in five geographically spread regions of Georgia, with the intention of informing tobacco control policy debates in Georgia, and other lower-income and middle-income countries.

\section{METHODS}

In November 2017, interviews were conducted with households in the cities of Tbilisi and Kutaisi, and the municipalities of Zugdidi, Gori and Akhaltsikhe (see the online supplementary map of Georgia). These regions were chosen to represent geographical diversity and varying proximity to border areas and Russian occupied territories.

Using the sampling frame of the 2016 parliamentary voter dataset, a total of 4345 individuals (one per household) were sampled across the five regions using multistage sampling. First, the areas were preliminarily stratified into rural and urban strata. Next, the primary sampling units (PSUs) were selected using probability proportional 
to population size. Thereafter, households (the secondary sampling unit) were selected using a random walking method in each PSU. This method was used because many homes do not have an address, and therefore it was not possible to provide location descriptions to the surveyors if a household was randomly selected. The random walk method is frequently used in Georgia. Within each selected household, the first adult responder was informed about the purpose of the study and if consent was obtained, was asked to list all current adult smokers in the household. If no adult smokers resided, only a brief general household questionnaire was administered. Otherwise, an adult smoker (the final sampling unit) was randomly selected from the list of resident smokers to complete the individual questionnaire.

If the selected respondent was not at home at the time of the interview, the interviewer returned up to three times to conduct the interview. If the respondent could not be located during the third visit, the interviewer randomly selected another smoking respondent (where available) from that household. Similarly, if the respondent refused to participate, the interviewer would select another participant (where available) in the same household. If all eligible smokers refused to participate, it was recorded as 'refuse to participate', and the interviewer went on to another household using the random step method. The interviews took approximately $15-20 \mathrm{~min}$. A randomly selected $10 \%$ of completed interviews (283 interviews) were cross-checked by an independent controller, and no major errors were found.

Of the 4345 households reached, 22\% reported not having a resident tobacco user. Of the 3388 remaining, 12\% either refused to participate or were not available for interview, and 2997 completed the interviews giving us a response rate of $88 \%$. The refusal rate in urban areas was significantly higher $(15 \%$, SE $0.7 \%)$ than in rural areas (4\%, SE 0.6\%). Smoker's absence was more common in urban areas (24\%, SE $0.8 \%)$ compared with rural areas (16\%, SE 1\%).

Although not designed to be nationally representative, the sample approximated the national averages across a range of characteristics including the average household size, average household income and average level of responder education. In terms of age, our sample under-represented the $71+$ age group, most likely due to premature deaths of smokers. ${ }^{9}$ The unemployment rates of the sample $(31 \%$, SE $0.8 \%)$ were higher than the broad definition of unemployment at the national level $(26 \%$ in 2015). ${ }^{10}$ This is because the sample over-represented urban areas which have higher rates of unemployment than rural areas. ${ }^{10}$

\section{RESULTS}

Among households with at least one smoker, 46\% (SE 0.6\%) of adults (18 years and older) identified themselves as current smokers, and 54\% (SE 0.6\%) as non-smokers. The majority of smokers are men-77\% (SE 0.6\%) and 11\% (SE 0.5\%) of men and women smoked in these households, respectively. Forty-four per cent (SE 0.9\%) of the smoking households had at least one child under the age of 18 . This means that many women and children in Georgia are exposed to secondhand smoke at home.

Filtered cigarettes (87\%, SE 0.4\%) were much more popular than unfiltered cigarettes (9\%, SE 0.4\%) with 3\% (SE 0.2\%) of tobacco users consuming both types, and 1\% (SE 0.1\%) of tobacco users preferring other products such as cigars or e-cigarettes.

The majority of smokers 95\% (SE 0.4\%) consumed tobacco daily. Men and women smoked on average 21 (SE 0.3) and 15
(SE 0.5) cigarettes per day, respectively. These observations are comparable with the national averages of 21.6 and 14.4 cigarettes per day, respectively. ${ }^{1}$ The smoking frequency was higher for those with less than secondary school education (23 cigarettes per day, SE 0.5 ) and for the unemployed (22 cigarettes per day, SE 0.6).

The legal age to buy tobacco in Georgia is 18 years, but $35 \%$ (SE 0.9\%) of smokers reported starting smoking before they reached that age. The initiation age varied significantly by gender, with 36\% (SE 0.9\%) of male and 19\% (SE 2.2\%) of female smokers reporting smoking before the age of 18 , respectively. Education was negatively correlated with initiation age-45\% (SE 3.5\%) of those with less than secondary school education began using tobacco before 18 , relative to $28 \%$ (SE $1.3 \%)$ of those with college education.

The majority of smokers (77\%, SE $0.8 \%)$ bought their last tobacco products at supermarkets, while $23 \%$ (SE $0.7 \%$ ) bought them at kiosks or other informal settings such as street-stands. Purchases in informal settings were more common in rural areas.

International brands represented 80\% (SE 0.8\%) of cigarette last purchased which is in line with national consumption trends (in 2017 84\% of the cigarette market consisted of imported brands while domestic brands made up the rest). ${ }^{11}$ Women displayed a stronger preference for imported tobacco products as $93 \%$ of the women (SE 1.4\%) bought international brands during their last purchase, compared with $78 \%$ of men (SE $0.8 \%)$. International brands were also more common in urban areas (84\%, SE 0.8\%), among those with college education (89\%, SE 0.9\%) and those in employment (91\%, SE 1\%).

The most commonly purchased brand was the international brand, Winston (15\%, SE 0.7\%), followed by local brand, Pirveli $(13 \%$, SE $0.6 \%)$, followed by a variety of other international brands: Kent (9\%, SE 0.5\%), Parliament (9\%, SE 0.5\%), Marlboro (8\%, SE 0.5\%) and Phillip Morris (8\%, SE 0.5\%). These self-reported buying patterns were closely aligned with the cigarette packs the respondents showed to the interviewers.

About 95\% (SE 0.5\%) of smokers bought cigarettes in packs, 9\% (SE 0.5\%) bought single sticks, and 6\% (SE 0.4\%) bought cartons. Most of those who bought singles also bought packs at the same time. Only 1\% (SE 0.1\%) smokers bought only singles.

Ninety-seven per cent (SE 0.3\%) of smokers bought their own cigarettes. When asked to show all cigarette packs currently available in the house, about 71\% (SE $0.8 \%$ ) of these smokers agreed to do so, 28\% (SE 0.8\%) said that there was no pack available in the house and 1\% (SE 0.2\%) either refused to show a pack or said they did not know if one existed in the house or not. Among those who showed a pack, 97\% (SE 0.4\%) showed one pack and 3\% (SE 0.4\%) showed two packs.

Women $(85 \%$, SE $2 \%)$, those living in urban areas $(74 \%$, SE $1 \%)$, college graduates (78\%, SE 1.2\%) and those employed (76\%, SE $1.5 \%)$ were the most likely to show a cigarette pack. There were some regional differences in the willingness to show a pack, with the municipality of Zugdidi standing out since only $60 \%$ (SE 3.3\%) of respondents were willing to show their packs. There was no correlation between the willingness to show a pack and household size, respondent age or the preferred cigarette brand. Because a pack's legal status can be determined by looking at it, some people may have been loathe to show their packs for this reason, and there may be a correlation between a pack's legal status and the owner's willingness to show it.

After removing outliers (2\% of observations), $25 \%$ of all the packs shown were priced between Georgian Lari 1.2 (GEL1.2) and GEL3, 50\% were priced between GEL3 and GEL4.2, and 25\% between GEL4.2 and GEL5.9. When the packs were split 

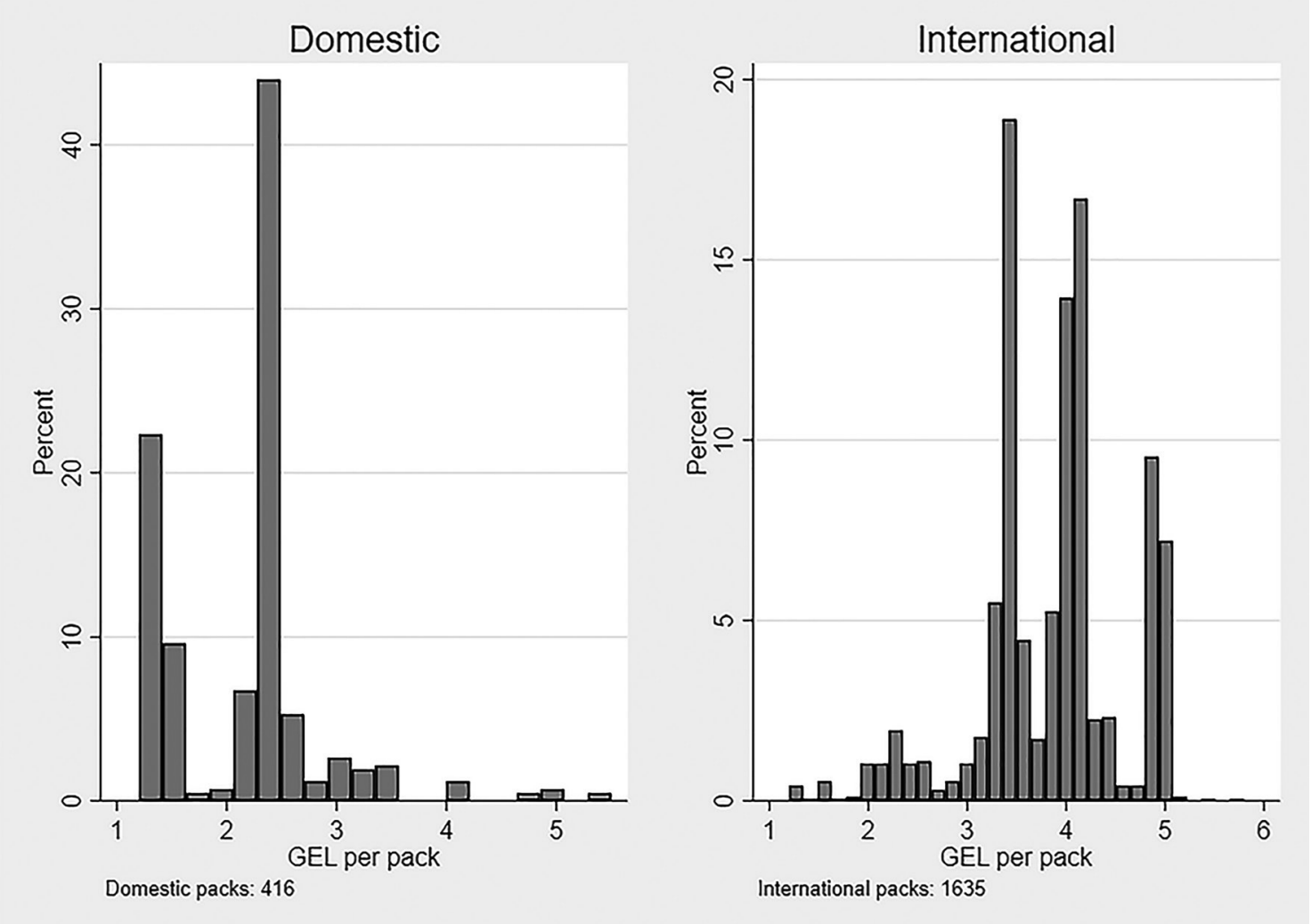

Figure 1 Price of cigarette boxes shown (histogram).

into domestic and international brands (figure 1), it was clear that domestic brands were significantly cheaper than international brands.

Men were significantly more likely to purchase cheap cigarettes, with nearly $10 \%$ (SE $0.7 \%$ ) of packs shown by men costing up to GEL2, relative to just $1.5 \%$ (SE $0.7 \%$ ) of packs shown by women (figure 2). This was in part due to men's preference for domestic brands as 79\% (SE 3\%) of the packs with prices up to GEL2 were domestic brands and only 21\% (SE 3\%) were international brands.

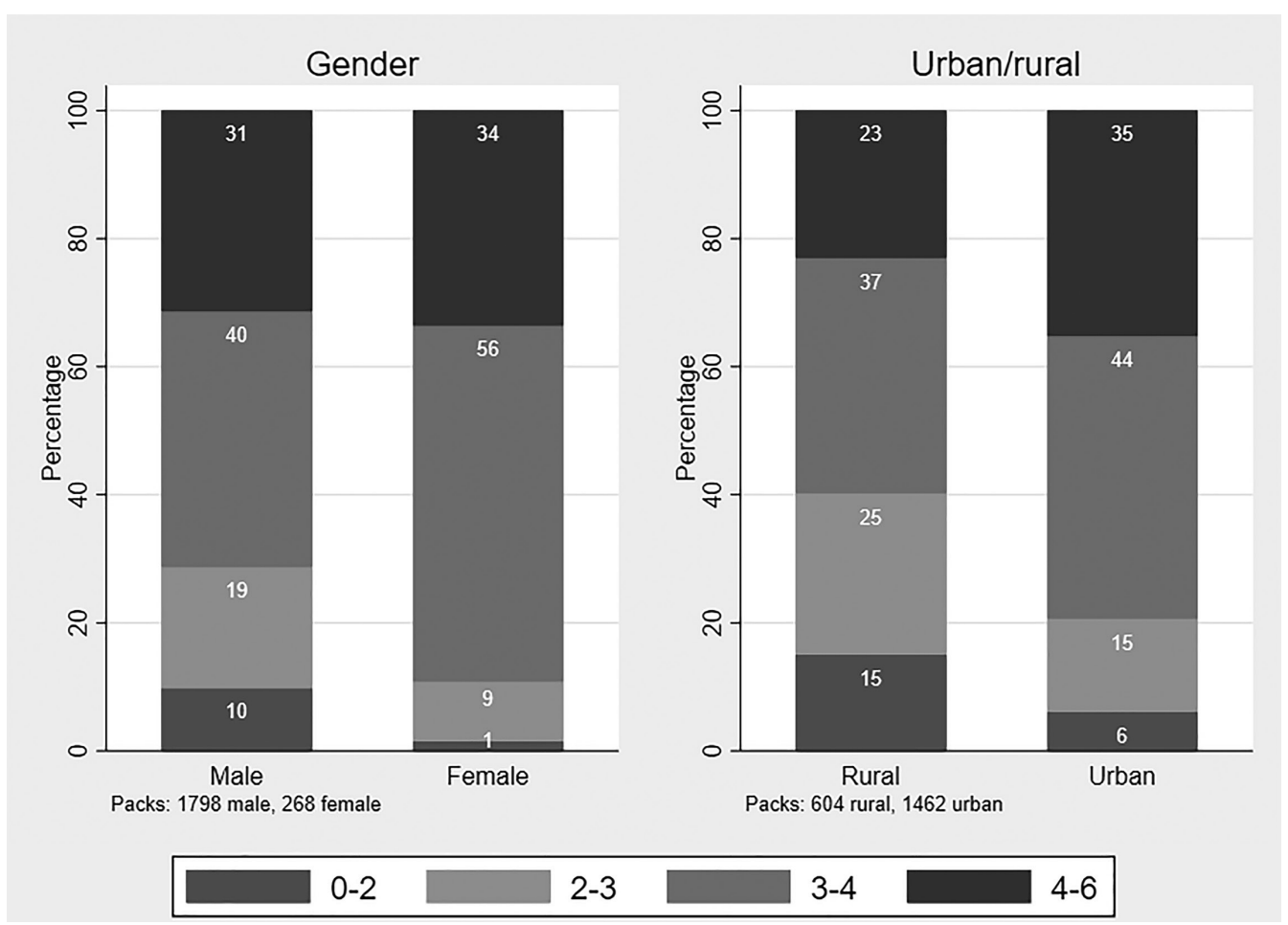

Figure 2 Pack price preferences, by gender and urbanity status. 
The average pack price in rural areas was a bit lower (GEL3.24, SE 0.05) compared with the urban areas (GEL3.66, SE 0.03). Domestic and international packs purchased in rural areas cost on average GEL2.05 (SE 0.05) and GEL3.73 (SE 0.04), respectively, while these packs cost GEL2.19 (SE 0.05) and GEL3.95 (SE 0.02) in urban areas, respectively. Cigarette packs with prices of GEL2 or less were markedly more common in rural areas $(15 \%$, SE1.5\%) than urban areas $(6 \%$, SE0.6\%).

All 2127 packs that were shown to interviewers (including the price outliers) were examined for the presence of a tax stamp and/ or health warning, and $98.5 \%$ (SE $0.3 \%$ ) of the shown packs had a Georgian tax stamp, 0.4\% (SE 0.1\%) had foreign tax stamps (seven packs had stamps from Abkhazia, one from Armenia and one from Russia), $0.5 \%$ (SE 0.2\%) might have had a tax stamp at some point in time but it was no longer clear and $0.6 \%$ (SE 0.1) had no tax stamp. With regard to the health warning, 99.1\% (SE $0.2 \%$ ) of the packs had a Georgian health warning, $0.3 \%$ (SE $0.1 \%$ ) had a foreign health warning (four packs had a warning from Abkhazia, one from Armenia and one from Russia), 0.1\% (SE $0.01 \%$ ) of the packs had a health warning that was not clear, and $0.5 \%$ (SE 0.1 ) of packs had no health warning at all. In total, $0.2 \%$ (SE $0.1 \%$ ) of the packs examined were missing both a Georgian tax stamp and a Georgian health warning, and 1.5\% (SE $0.2 \%$ ) of the packs were missing either the Georgian tax stamp or the Georgian health warning or it was unclear.

It was significantly more common for cigarette packs from Zugdidi to be missing a clear Georgian tax stamp and/or missing a clear Georgian health warning than in the other regions. On average, 6\% (SE 1.4\%) of packs in Zugdidi were missing clear Georgian tax stamps and/or health warnings, relative to $0.8 \%$ (SE $0.3 \%$ ) of packs in Tbilisi, $0.3 \%$ (SE $0.3 \%$ ) of packs in Kutaisi, $0.6 \%$ (SE 0.4\%) of packs in Akhaltsikhe and 1.6\% (SE 0.7\%) of packs in Gori. Individuals that showed illicit cigarette packs were significantly more likely to have bought their last pack at informal locations such as street stands or house-shops (15\%, SE 3.4\%) than supermarkets or kiosks.

There was no significant difference between men and women's likelihood to have a pack missing a clear Georgian tax stamp and/or health warning, nor a difference by urban and rural location, or work status. The brands of the cigarette boxes that were missing clear Georgian tax stamps and/or health warnings are reflected in table 1 .

Within each brand, the price paid for the packs missing the Georgian tax stamp and/or health warning was not significantly different to those that had the Georgian tax stamp and/or health warning, with the exception of the Sobranie brand. The two Sobranie packs without Georgian tax stamps and health warnings were priced at GEL1.5 and GEL2 while the average price of the other 86 Sobranie packs with the appropriate tax stamps and health warnings was GEL4.8 (SE 0.03).

None of the Manchester packs (10 packs) had Georgian tax stamps and/or health warnings. While Manchester cigarettes made up only $0.5 \%$ of the total packs shown, they represented $31 \%$ of the total illicit packs. The small sample size made inference about the other brands difficult.

When asked about associations related to illicit cigarettes, $35 \%$ (SE $0.8 \%$ ) of tobacco users cited the low price, 13\% (SE $0.6 \%$ ) thought that illicit cigarettes could be of lower quality, 9\% (SE 0.5\%) referred to not paying taxes, 9\% (SE 0.5\%) said that the health warning was not legible and 6\% (SE 0.4\%) said that illegal cigarettes could be purchased at unregistered outlets. About 4\% (SE $0.3 \%$ ) of tobacco users refused to answer this question while 24\% (SE 0.8\%) did not know the answer.

On average, $73 \%$ (SE $0.8 \%$ ) of smokers were unaware of any illicit cigarette trade in their area, 2\% (SE 0.3\%) were aware of some trade, $24 \%(0.8 \%)$ said they were not sure and $1 \%$ (SE $0.2 \%$ ) refused to answer the question (figure 3 ). Awareness varied markedly by region, with $9 \%$ (SE 1.3\%) of individuals in Zugdidi indicating awareness of illicit trade, relative to $1 \%$ (SE 0.3\%) in Tbilisi and zero in Kutaisi, Akhaltsikhe and Gori. The degree of uncertainty was highest in Kutaisi where 39\% (SE 2.2\%) did not know if illicit trade existed in their area. Kutaisi was followed by Zugdidi, Akhaltsikhe, Gori and Tbilisi where 33\% (SE 2.1\%), 28\% (SE 2\%), 25\% (SE 1.9\%) and 10\% (SE $1 \%)$ of tobacco users were not aware of illicit cigarette trade, respectively.

Awareness of illicit cigarettes was higher among those that bought tobacco at sources such as street stands or house-shops

Table 1 Number of packs missing clear Georgian tax stamps and/or health warnings, by brand

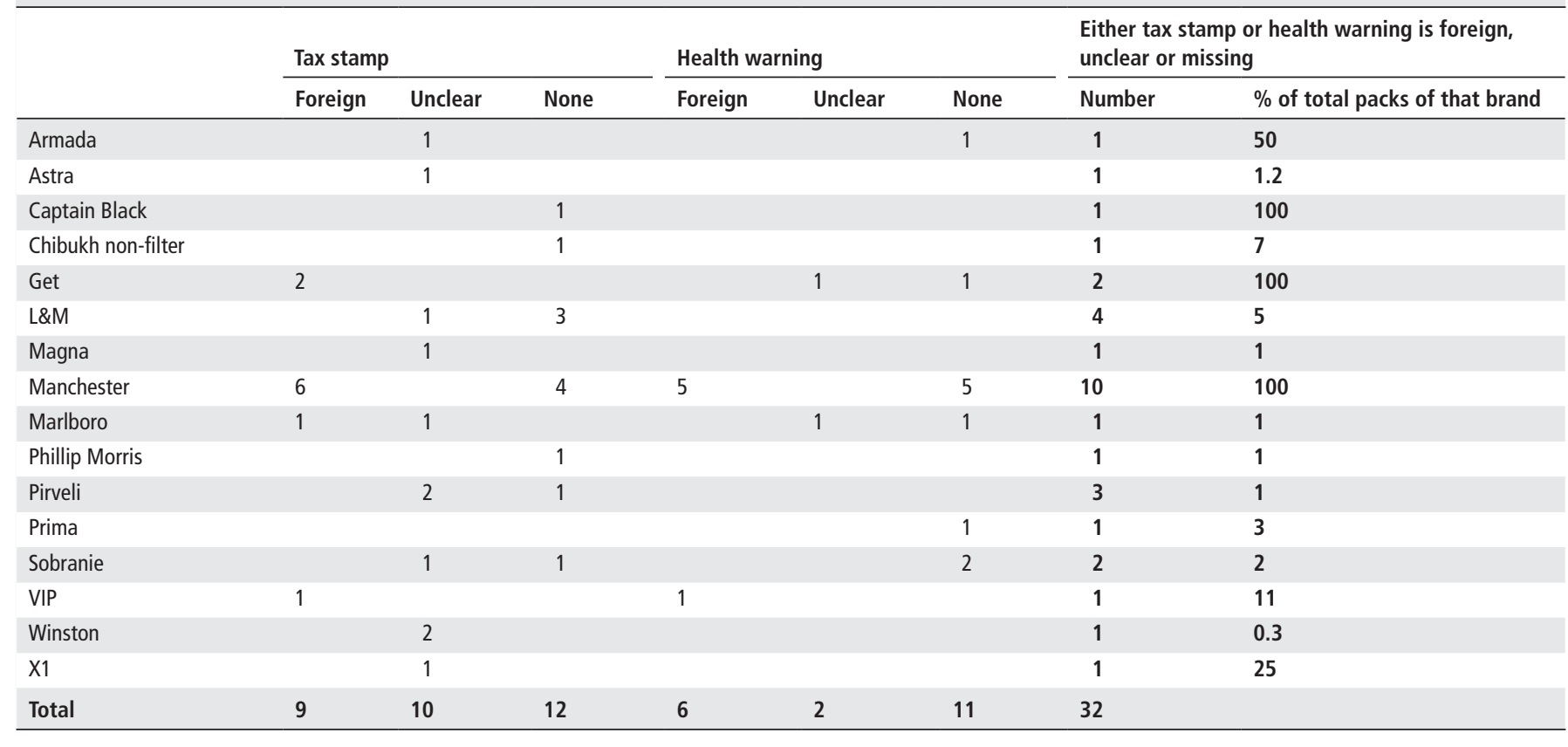




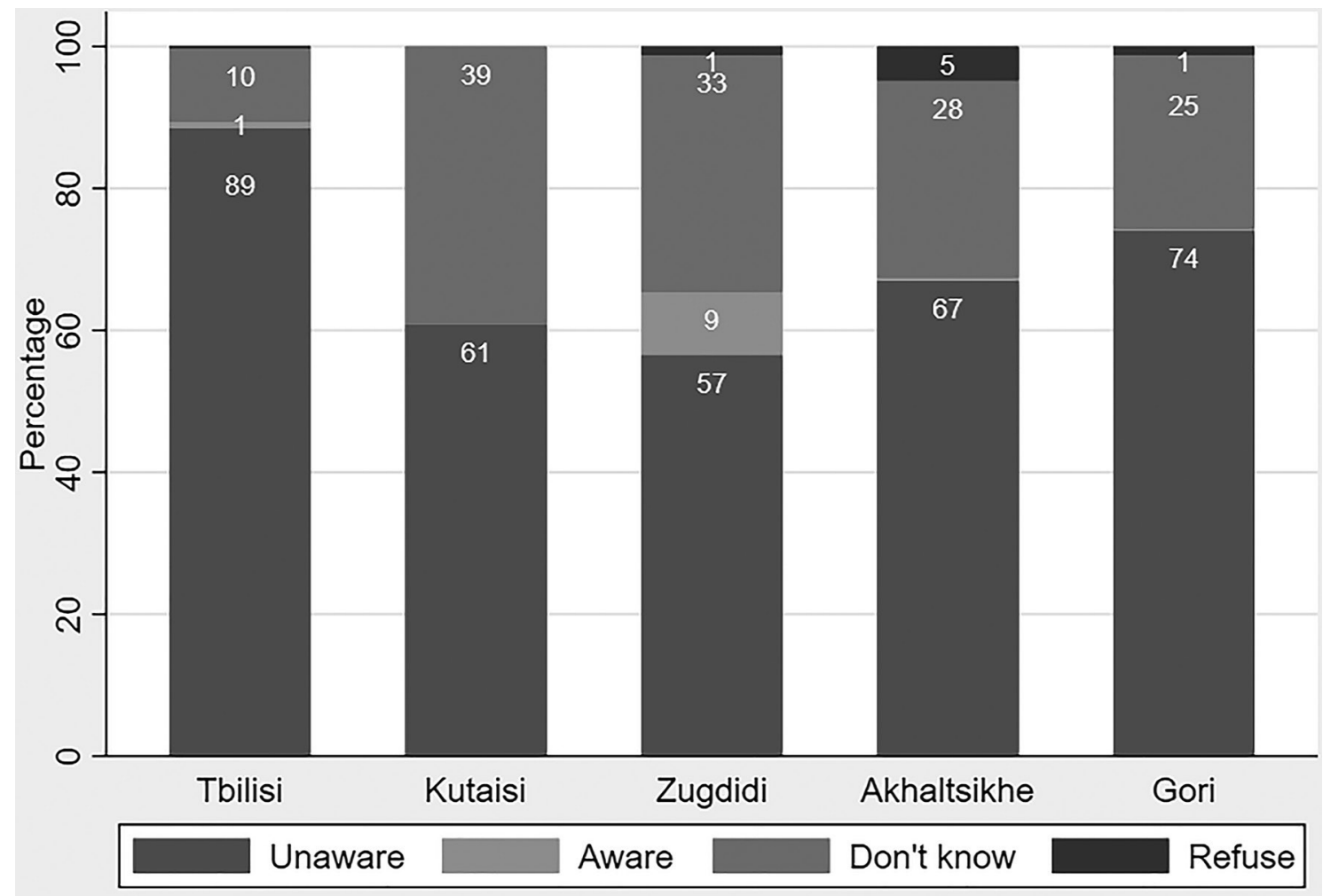

Individuals: 997 Tbilisi, 498 Kutaisi, 500 Zugdidi, 500 Akhaltsikhe, 502 Gori

Figure 3 Awareness of illicit cigarette trade, by region.

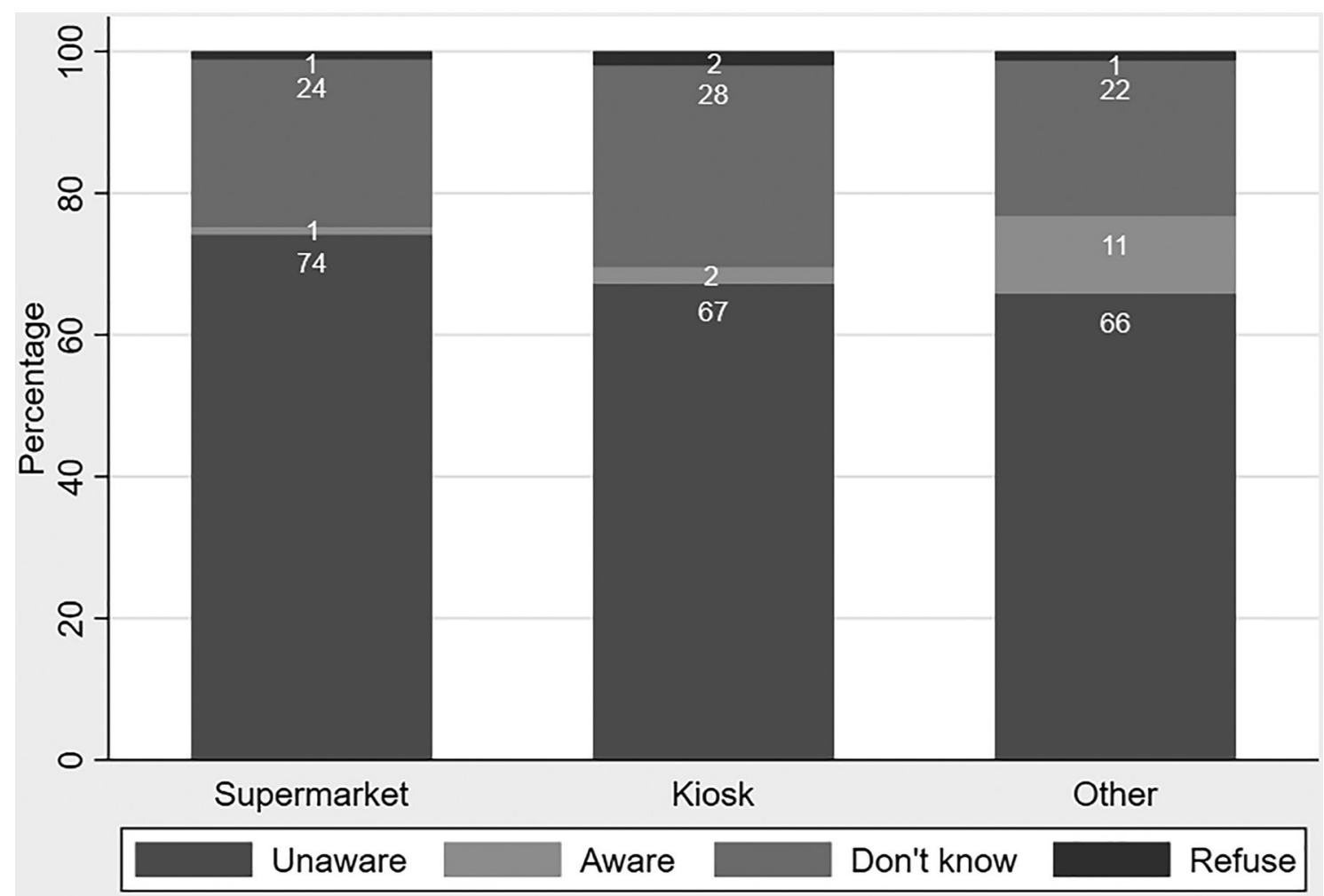

Individuals: 2245 supermarket, 506 kiosk, 155 other

Figure 4 Awareness of illicit cigarette trade, by place where they last purchased their tobacco. 
(11\%, SE 2.5\%), than those purchasing from kiosks (2\%, SE $0.7 \%)$ and those purchasing from supermarkets (1\%, SE $0.2 \%)$ as seen in figure 4. Individuals that were aware of illicit trade in their area were less likely to show the interviewer a pack of cigarettes (52\%, SE $6.9 \%$ showed packs) than those unaware of illicit trade in their area $(72 \%$, SE $1.0 \%$ showed packs). No correlation was found between an individual's age or education and their awareness of illicit trade, and neither was there any significant difference in awareness between those that favoured international brands and those that smoked domestic brands.

Among those that were aware of illicit trade in their area (only 55 individuals), 6\% (SE 2.2\%) felt the issue was very small, 16\% (SE 3.5\%) small, 49\% (SE 4.8\%) moderate, 16\% (SE 3.5\%) large, 6\% (SE 2.5\%) very large while 7\% (SE 2.5\%) said they were not sure of the size of the issue.

\section{DISCUSSION}

This paper generates insight into the degree of illicit cigarette consumption and the public awareness and perceptions of illicit cigarette trade in Georgia. We found very little evidence of such trade, as just $1.5 \%$ of the inspected cigarette packs lacked a clear Georgian tax stamp and/or health warning. This is a remarkable achievement given that in the early 2000s, one-third to twothirds of the market was reported to be illegal.

Zugdidi had the highest share of illicit packs, and its respondents were the most aware of illicit cigarette trade. Zugdidi lies in close proximity to the Georgian territory of Abkhazia controlled by the Russian government which makes it vulnerable to illicit cigarettes coming from Russia.

The most common illicit brand was Manchester. All 10 packs of this brand were illegal. The Manchester brand was previously identified as a 'Cheap White' brand manufactured in Russia. ${ }^{12}$ A popular Russian brand Sobranie also appeared among illicit cigarettes, and these packs were priced significantly lower than other legal Sobranie packs present in the market.

Individuals that purchased their last pack at informal locations such as street stands or kiosks were more likely to have an illicit cigarette pack in their house and were more aware of illicit cigarette trade in their area. This calls for spot checks by authorities on cigarette sales at these locations.

A limitation of our study approach is that we could not test the tax stamps for their legitimacy due to limited budget. Furthermore, it is a concern that $28 \%$ of the smokers claimed that they did not have a cigarette pack at home at the time of the interview. If these respondents were concealing illicit packs out of fear of some negative consequences, our study significantly underestimated the size of illicit trade in Georgia. However, the Georgia Revenue Service and Euromonitor ${ }^{13}{ }^{14}$ believes that the illicit cigarette trade in Georgia is minimal. There might be other reasons for not showing/not having a pack at home: buying single cigarettes only; rolling their own cigarettes but claiming to smoke manufactured cigarettes due to their perceived higher status; reporting to smoke a certain aspirational brand, but smoking a brand with lower social status; or hiding the fact that they smoke (and thus their cigarette boxes) from other household members. Nonetheless, the fact that Zugdidi residents were less likely to show their packs than the residents of other regions, coupled with the higher than average rates of illicit cigarettes in Zugdidi suggests that illicit pack concealment may be an issue. To fill this knowledge gap, we have launched further investigation via focus groups to better understand the motivation of these smokers.

\section{CONCLUSION}

Despite the tobacco industry refrain that higher tobacco taxes drive up illicit trade, both the international and Georgian experience demonstrate no, or at best limited, relationship between cigarette taxes and illicit trade..$^{15}$ In Ukraine, for example, a method similar to ours revealed that substantial tobacco tax increases were followed by a decline in the consumption of smuggled cigarettes. ${ }^{16}$

In Georgia, the 2004 government reforms led to vast improvements in tax administration and reduction in corruption which, in combination with an advanced technological solution, resulted in a massive decline in illicit cigarette trade in Georgia. ${ }^{13} 14$ Provided the tax administration remains strong and vigilant, policy-makers in Georgia do not have to worry that the planned increases in tobacco excise taxes will result in a massive influx of illicit cigarettes to the market. Since Georgia plans to reach the European Union's tax level by 2024 (€90 per 1000 cigarettes) it needs to increase its cigarette taxes regularly and substantially, since the 2018 average tax rate is below $€ 30$ per 1000 cigarettes.

Despite Georgia's low levels of illicit cigarette trade, the tobacco industry continues to use the illicit trade argument to push back on planned tobacco tax increase. Therefore, Georgia should consider ratifying the Framework Convention on Tobacco Control's Protocol to Eliminate Illicit Trade in Tobacco Products to strengthen its international standing in controlling illicit cigarette trade, both domestically and regionally. Georgia would be a welcomed member of the protocol due to its experience in controlling the cigarette supply chain. In addition, being a part of the protocol would help Georgia to respond adequately to the industry arguments and to enhance international collaboration in controlling the transit of illicit products through its territory.

\section{What this paper adds}

- Despite the tobacco industry claims of an imminent thread of illicit cigarette trade, in Georgia illegal cigarettes are rarely observed among smokers despite recent increases in tobacco taxes.

- However, there seem to be regional differences in the size of the illicit cigarette market and in the willingness to show a cigarette pack for inspection.

Acknowledgements We would like to thank Mike Bowling for assistance in designing the sampling frame, Kakha Gvinianidze for his support, the surveyors for their hard work and all survey respondents.

Contributor HR conceptualised the research and designed the questionnaires with the input from the rest of the team. GB is the principal investigator and managed the project in Georgia. IK managed the data collection. ML and IK analysed the data. The results were synthesised and written by ML and $H R$, with inputs from GB and IK.

Funding This research was made possible by funding from Cancer Research UK (IRMA number 30845).

Competing interests None declared.

Patient consent Not required.

Ethics approval The survey was executed following the ethics rules of the Republic of Georgia.

Provenance and peer review Not commissioned; externally peer reviewed.

\section{ORCID iD}

George Bakhturidze http://orcid.org/0000-0002-5578-5189

\section{REFERENCES}

1 Sturua L. Non-communicable Diseases Risk-factors STEPS survey results. Country Coordination Council on Non-communicable Diseases Prevention and Control Expanded meeting, Tbilisi. 2017. 
2 Gilmore A, Pomerleau J, McKee M, et al. Prevalence of smoking in 8 countries of the former Soviet Union: results from the living conditions, lifestyles and health study. Am J Public Health 2004;94:2177-87.

3 Shalutashvili A, Ross H, Watt J, et al. Tobacco Economic Study in Georgia since the fall of the Soviet Union. Tbilisi: FCTC Implementation and Monitoring Center in Georgia, 2007.

4 State Department of Statistics for Georgia. 2004 http://www.geostat.ge/index.php? action=search\&lang=eng

5 State Department for Statistics of Georgia. Supply and Use of Tobacco Goods in Georgia. Tbilisi, 2002

6 Kobeshavidze G, Meskhishvii G, Bakhturidze G, et al. Cigarette smuggling and illicit trade problems in Georgia. Tbilisi: Georgian National Counter Tobacco Center, 2003.

7 Krasovsky K. The impact of changes in excise rates on the cigarette market and budget revenues in Georgia. Unpublished manuscript in Russian 2013.

8 Zoide A. The tobacco smuggling rate in Georgia doesn't exceeds 3\%. Tbilisi, Georgia, 2017. https://commersant.ge/ge/post/akaki-zoidze-saqartveloshi-tambaqoskontrabanda-3-s-ar-agemateba-rac-dzalian-mcire-machvenebelia
9 Hakkert R. Population dynamics in Georgia - an overview based on the 2014 general population census data. Tbilisi: National Statistics Office of Georgia and United Nations Population Fund, 2017.

10 Kakulia M, Kapanadze N, Lomjaria V, et al. Structure of Unemployment and Structural Unemployment in Georgia. Georgian Foundation for Strategic and International Studies (Rondeli Foundation) and Friedrich-Ebert-Stiftung. 2016.

11 State Department of Statistics for Georgia. 2018 http://www.geostat.ge/index.php? action=search\&lang=eng

12 Ross H, Vellios N, Clegg Smith K, et al. A closer look at "Cheap White" cigarettes. Tobacco Control 2015.

13 Euromonitor International. Cigarettes in Georgia: Euromonitor International, 2018.

14 Euromonitor International. Cigarettes in Georgia: Euromonitor International, 2016.

15 U.S. National Cancer Institute and World Health Organization. The Economics of Tobacco and Tobacco Control. . Bethesda, MD: (N. I. U.S. Department of Health and Human Services, \& C. W. and Geneva, 2016. NIH Publication No. 16-CA-8029A.

16 Andreeva T, Kharchenko N, Krasovsky K, et al. Ukraine Global Adult Tobacco Survey

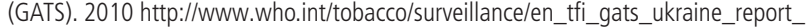
2010.pdf 